\title{
Assessment of Fear of COVID-19 in Older Adults: Validation of the Fear of COVID-19 Scale
}

\author{
Tomás Caycho-Rodríguez ${ }^{1,2}$ (D) - José M. Tomás ${ }^{3} \cdot$ Miguel Barboza-Palomino $^{1}$ • \\ José Ventura-León $^{1} \cdot$ Miguel Gallegos ${ }^{4,5} \cdot$ Mario Reyes-Bossio $^{6} \cdot$ Lindsey W. Vilca $^{7}$
}

Accepted: 11 November 2020 / Published online: 6 January 2021

C Springer Science+Business Media, LLC, part of Springer Nature 2021

\begin{abstract}
There is no information in Peru on the prevalence of mental health problems associated with COVID-19 in older adults. In this sense, the aim of the study was to gather evidence on the factor structure, criterion-related validity, and reliability of the Spanish version of the Fear of COVID-19 Scale (FCV-19S) in this population. The participants were 400 older adults (mean age $=68.04, \mathrm{SD}=6.41$ ), who were administered the Fear of COVID19 Scale, Revised Mental Health Inventory-5, Patient Health Questionnaire-2 items, and Generalized Anxiety Disorder Scale 2 items. Structural equation models were estimated, specifically confirmatory factor analysis (CFA), bifactor CFA, and structural models with latent variables (SEM). Internal consistency was estimated with composite reliability indexes (CRI) and omega coefficients. A bifactor model with both a general factor underlying all items plus a specific factor underlying items 1, 2, 4, and 5 representing the emotional response to COVID better represents the factor structure of the scale. This structure had adequate fit and good reliability, and additionally fear of COVID had a large effect on mental health. In general, women had more fear than men, having more information on COVID was associated to more fear, while having family or friends affected by COVID did not related to fear of the virus. The Spanish version of the Fear of COVID-19 Scale presents evidence of validity and reliability to assess fear of COVID-19 in the Peruvian older adult population.
\end{abstract}

Keywords Older adults $\cdot$ Reliability $\cdot$ Fear of COVID- $19 \cdot$ Bifactor model $\cdot$ Validity

COVID-19, caused by the severe acute respiratory syndrome coronavirus (SARS-CoV-2), has spread rapidly throughout the world (Huang and Zhao 2020), affecting 188 countries with 13,135,616 confirmed cases and 573,869 of deaths, and increasing (data obtained from https:// coronavirus.jhu.edu/map.html, on July 17, 2020). This disease presents a higher risk of mortality in people with comorbidity and older adults (Morley and Vellas 2020). In Latin

Tomás Caycho-Rodríguez

tomas.caycho@upn.pe

Extended author information available on the last page of the article 
America and the Caribbean, the first case was reported on February 25, 2020, in Brazil (Rodriguez-Morales et al. 2020a), and then, its presence was reported in different countries of the region (Rodriguez-Morales et al. 2020b). In Peru, given the appearance of the first cases of COVID-19 (the first case was announced on March 6, 2020), the government ordered social, economic, political, and health measures to prevent and control contagion. Thus, for example, to prevent the transmission of the virus, a period of compulsory social isolation began on March 16, which has been extended until June 30. Despite this effort, the country occupies the fifth place worldwide and the second in Latin America regarding the total number of cases by number of inhabitants (https://coronavirus.jhu.edu/map.html), with 330,123 confirmed cases and 12,054 deaths, of which 8354 were older adults (data obtained from https://covid19.minsa.gob.pe/sala_situacional.asp, on July 17, 2020). To the aforementioned, the deficiency in the health system and hospital infrastructure constitutes a problem that needs to be improved to control the COVID-19 pandemic in Peru and other Latin American countries (Gozzer et al. 2020; Sánchez-Duque et al. 2020).

The rapid spread of COVID-19 has led the scientific community to focus its efforts on generating treatments, vaccines, and methods of disease prevention (Bitan et al. 2020; O'Brien et al. 2020). However, the increase in confirmed cases, the high mortality rate (between $1.5 \%$ and $3.6 \%$; Baud et al. 2020), the absence of an effective vaccine to counteract the disease, and the mandatory changes to decrease the behaviors that increase the risk of contagion (such as isolation and social distancing) have caused the population to experience various mental health problems, such as anxiety, depression, stress, and fear of contracting the virus (HuarcayaVictoria 2020; Rajkumar 2020). This situation also affects the health and well-being of the older adults (Steinman et al. 2020).

In Peru, mental health problems are common in older adults, with a prevalence of depression symptoms of $81.2 \%$ in those who are institutionalized (Dominguez-Lara and Centeno-Leyva 2017) and $18.7 \%$ in the non-institutionalized (Caycho-Rodríguez et al. 2019a). Furthermore, between 41.7 and $54.9 \%$ of older adults felt lack of company and social isolation (Caycho-Rodríguez et al. 2020a), while there is a high prevalence of inability to carry out daily activities and relating to others, communication problems, and lack of adaptation to their social environment that negatively affect their quality of life (Caycho-Rodríguez et al. $2019 \mathrm{~b}$ ). Finally, in the last year, $30.5 \%$ of older Peruvian adults have thought one or many times that life is not worth it, $21 \%$ have wanted one or many times to be dead, and $12.5 \%$ have thought one or many times to put an end to their life (Caycho-Rodríguez et al. 2020b). Considering this scenario, the COVID-19 pandemic could increase the risk of developing mental health problems or aggravating existing ones, affecting older adults' daily functioning (Yang et al. 2020).

Regarding fear, it can be presented in different ways, such as fear of becoming infected, fear of being in contact with possibly contaminated objects, fear of foreigners who may carry the virus, or fear of the socioeconomic consequences of the pandemic (Taylor 2019; Taylor et al. 2020). Although fear can be considered an adaptive emotion that allows facing potential threats, when it is excessive, it can become maladaptive (Mertens et al. 2020). On one hand, studies in the context of previous pandemics have shown that the absence of fear can be harmful to people, since it influences the decrease in hygiene behaviors (such as hand washing) and ignoring measures to stop the spread of diseases, such as physical distancing (Taylor 2019). On the other hand, an excessive level of fear has negative effects on well-being, generating phobias or symptoms of social anxiety (Asmundson and Taylor 2020). 
Considering all these, the study of fear is important for psychological well-being and influences the way in which an individual adheres to preventive measures against the disease (Taylor 2019). Unfortunately, in Peru, there is no information on the prevalence of psychological responses to fear of COVID-19, nor how they are distributed in the older population. Added to this is the absence of an appropriate psychometric instrument that allows a valid and reliable measurement of fear of COVID-19.

In response to this need, the Fear of COVID-19 Scale (FCV-19S; Ahorsu et al. 2020) was recently developed with the aim of assessing fear of COVID-19. The FCV-19S is a short, easy to apply, seven-item instrument. In the initial study, using classical theory of tests and the Rasch model, it was reported that the seven items grouped into a single factor had acceptable corrected item-total correlations and significant factor loadings (from .66 to .74). Furthermore, the reliability as internal consistency $(\alpha=.82)$ and test-retest $(\mathrm{ICC}=.72)$ were adequate, while the concurrent validity assessment showed significant relationships with hospital depression and perceived vulnerability to illness.

The FCV-19S has been translated into various cultural contexts such as Bangladesh (Sakib et al. 2020), Turkey (Haktanir et al. 2020), Italy (Soraci et al. 2020), Eastern Europe (Reznik et al. 2020), Saudi Arabia (Alyami et al. 2020), Israel (Bitan et al. 2020), New Zealand (Winter et al. 2020), Japan (Masuyama et al. 2020), Cuba (Broche-Pérez et al. 2020), Peru (HuarcayaVictoria et al. 2020), and Greece (Tsipropoulou et al. 2020). All these studies have shown evidence of reliability based on different coefficients such as Cronbach's alpha, Omega, Guttmann's lambda, or composite reliability. Regarding factor structure, most of the studies supported the presence of a single dimension. However, Bitan et al. (2020) and Reznik et al. (2020) reported the presence of two factors: the first related to physiological responses to COVID-19 (items 3, 6, and 7) and the second one that represents the emotional responses to COVID-19 (items 1, 2, 4, and 5). However, the two-factor model may have limitations to capture multidimensionality of fear of COVID-19, because the variance of every item may be associated to both a global factor and simultaneously to a specific factor (Reise 2012).

In this sense, the studies of Huarcaya-Victoria et al. (2020) and Masuyama et al. (2020) tested an alternative model to those reported previously: a bifactor model (see Reise et al. 2010for a review). In this model, each item loads in both a general (overall) factor as well as in a specific factor, and all factors are specified as orthogonal. That way the proportion of variance due to the general as well as specific factors may be estimated (Raykov and Pohl 2013). Regarding the FCV-19S, the bifactor model would translate into a general factor of fear of COVID-19, which explains most of the variance in line with Ahorsu et al. (2020), and two orthogonal specific factors (physiological and emotional fear responses) as indicated in other validation studies (Bitan et al. 2020; Reznik et al. 2020). The bifactor model assesses the effects of multidimensionality of the FCV-19S in the total score as well as every subscale (Reise 2012). If the specific factors explain very little variance, the recommendation is to calculate a global score instead of scores for each subscale (or specific factor). On the other hand, more percentage of variance related to each specific factor would suggest the use of each subscale for further analyses (Rodriguez et al. 2016a, b).

Although there is a validated Spanish version for Peruvian general population (HuarcayaVictoria et al. 2020), the study only included the participation of 71 people over 60 years of age. In this sense, there is no psychometric evidence that supports the use of the FCV-19S in older adults in Peru or any other Latin American country. Also, given that Peru is one of the countries with the highest number of infections in the world, it is necessary to carry out an epidemiological study on the relationship between the mental health of older adults and fear of 
COVID-19. Therefore, the objective of the study was to evaluate the psychometric properties of the FCV-19S for use in older adults. Specifically, the evidence of validity based on internal structure, in relation to other variables and reliability, was evaluated.

\section{Method}

\section{Design, Sample, and Procedure}

The study was instrumental (Ato et al., 2013). The participants were older adults from the city of Lima. The sample size was determined with Soper's (2020) software that considers the number of observed and latent variables in the model, the size of the anticipated effect $(\lambda=0.3)$, the desired statistical significance $(\alpha=0.05)$, and the level of statistical power $(1-\beta=0.95)$. Inclusion criteria for participation were (1) being 60 years or older and (2) not have intellectual difficulties that prevent understanding the instructions and the content of the survey. Snowball sampling was used (Atkinson and Flint 2004). Upon identifying an individual who met the established inclusion criteria, he/she was asked to suggest others who might be interested to participate in the study. Their telephone number was used to contact them. Once it was identified that the individual met the inclusion criteria and agreed to participate, his/her email address or, failing that, the email address of a close relative was requested to send the online survey. This type of survey has been used in other studies with old people during the pandemic of COVID-19 (Carriedo et al. 2020). Online snowball sampling has been shown to be adequate to contact participants from different places and reaching higher response rates than other sampling strategies (Baltar and Brunet 2012).

The final sample was composed of 400 older adults with range age from 60 to 86 years (mean $=68.04, \mathrm{SD}=6.41$ ). $68.3 \%$ were women. Regarding marital status, $36.5 \%$ were married, $32.8 \%$ lived with a partner, $21.2 \%$ were widows or widowers, $4.9 \%$ were divorced, and $4.6 \%$ single. $82.8 \%$ of the sample were retired, $12.8 \%$ unemployed, and $4.4 \%$ were doing some kind of job or business. Most of the samples were not diagnosed with COVID-19 (98\%), but many had family $(82.3 \%)$ or friends $(61.3 \%)$ diagnosed with the disease. Finally, in the last 2 weeks prior to the study, more than half of the sample $(50.8 \%)$ reported having read or heard information about the coronavirus for around 1 to $3 \mathrm{~h}$.

No pilot study was made, given that a prior research applied the Spanish version of the FCV-19S to a small group of Peruvian older adults (Huarcaya-Victoria et al. 2020), without reporting inconveniences in the use of the instrument.

The study was conducted during May 29 and June 25, 2020. An online survey was distributed to participants. Participants gave their informed consent online and answered the anonymous survey in approximately $15 \mathrm{~min}$ via Google Form. In this way, it was sought to guarantee a greater scope and ease of access. In order to submit their responses, participants had to answer all the questions on the survey. No compensation was given for participation in the study. The instruments were randomized in blocks to avoid order effects. The study was reviewed and approved by the Ethics Committee of the Universidad Privada del Norte, to which the corresponding author is affiliated (Registration number: 20203001); likewise, the procedures used adhered to the principles of the Declaration of Helsinki. 


\section{Measures}

Sociodemographic indicators were developed ad hoc for the study. It gathers information on age, sex, marital status, diagnosis of COVID in the participant, family or friends, and hours thinking, sawing, or listening to information on COVID-19 ( 1 to $3 \mathrm{~h}, 3$ to $5 \mathrm{~h}, 5$ to $7 \mathrm{~h}$, and more than $7 \mathrm{~h}$ ).

Fear of COVID-19 Scale (FCV-19S, Ahorsu et al. 2020) This seven-item scale evaluates fear of COVID-19 with a five-point Likert-type response scale from 1 (= strongly disagree) to 5 (= strongly agree). The total score is obtained from the sum of the scores for each item and ranges from a minimum of 7 to a maximum of 35. A higher score is indicative of greater fear of COVID-19. The Peruvian version of the FCV-19S was used (Huarcaya-Victoria et al. 2020).

Revised Mental Health Inventory-5 (MHI-5; Berwick et al. 1991) The revised and validated Spanish version by Rivera-Riquelme et al. (2019) was used. The MHI-5 is a short version of the 38-item Mental Health Inventory (Veit and Ware 1983) that assesses symptoms of anxiety, depression, and general distress during the last 2 weeks, based on five questions: (1) how often have you felt very nervous?; (2) how often have you felt calm and peaceful?; (3) how often have you felt discouraged or sad?; (4) how often have you felt happy?; and (5) how often have you felt so sad that nothing could cheer you up? All items have a 4-point response scale ranging from 0 (= never) to 3 (= always). Items 1,3 , and 5 are reversed.

Patient Health Questionnaire-2 Item (PHQ-2; Kroenke et al. 2003) The PHQ-2 is made up of two items that evaluate the frequency of depressive symptoms experienced in the 2 weeks prior to administration. The Spanish version by Caycho-Rodríguez et al. (2020c, d) was used. This version presented adequate psychometric properties. The items are (1) feeling discouraged, depressed, or hopeless and (2) little interest or pleasure in doing things. The two items have four response options from 0 (= not at all) to 3 (= almost every day). Total scores range from 0 to 6 , and a score $\geq 3$ indicates a greater severity of depressive symptoms.

Generalized Anxiety Disorder Scale 2 Item (GAD-2; Kroenke et al. 2007) It is a self-report measure with two items that are basic criteria for diagnosing the presence and severity of symptoms of generalized anxiety disorder. The Spanish version by Caycho-Rodríguez et al. (2020e) was employed. This version has shown good psychometric properties. Specifically, the GAD-2 asks how often respondents have been bothered by anxiety symptoms in the past 2 weeks. The items are (1) feeling nervous, anxious, or on edge and (2) not being able to stop worrying or not being able to control the worry. Each item has four response options from 0 (= not at all) to 3 (= almost every day). The sum of the scores of both items allows obtaining a total score that varies between 0 and 6 , where a value $\geq 3$ indicates the presence of a clinically relevant anxiety disorder.

\section{Statistical Analyses}

Several structural equation models, specifically confirmatory factor analyses (CFA), bifactor CFA, and structural models with latent variables, have been estimated. Robust estimation, specifically WLSMV (weighted least Squares mean and variance corrected), was used for all 
the models to overcome the non-normality and ordinal nature of the items (Hancock and Mueller 2013). Fit of the models was assessed by means of several indices and statistics from different families (Tanaka 1993): (a) chi-square; (b) comparative fit index (CFI); (c) the standardized root mean residual (SRMR); and (d) root mean square error of approximation (RMSEA) with its $90 \%$ confidence interval. Criteria for acceptable model fit were CFI above .90 (better fit above .95) and RMSEA and SRMR below .08 (Marsh et al. 2004). Internal consistency was estimated with composite reliability indexes (CRI) and relative omega estimate of reliability (Dueber 2017) to overcome the limitations of Cronbach's alpha (Hancock and An 2018). Validity of scales was assessed with a structural model relating the factors in the scale with relevant variables. All models were estimated with Mplus 8.3 (Muthén and Muthén 1998-2017).

\section{Results}

\section{Factor Structure}

Previous studies on the factor structure of the FCV-19S have tested three different structures: a one factor model, two correlated substantive factors, and a bifactor structure in which an overall general factor is declared to underlie to all seven items, while two (uncorrelated) specific factors simultaneously underlie the scale items. With these models in mind, but adding two other theoretical models, we have tested five alternative or competitive models:

- Model 1. One single factor underlying the seven items of the scale. Most evidence in different countries has found evidence for a single dimension (see introduction for references).

- Model 2. Two correlated factors: emotional response to COVID-19 (factor 1); items 1, 2, 4, and 5; and physiological response to COVID-19 (factor 2), items 3, 6, and 7. This model is based in Bitan et al. (2020) and Reznik et al. (2020).

- Model 3. Bifactor model: A general factor underlying all items, plus the two specific factors in model 2 (emotional and physiological response). All three factors are specified uncorrelated. This model is based in the Peruvian validation of the scale (HuarcayaVictoria et al. 2020) and also in Masuyama et al. (2020)

- Model 4. Bifactor model with only specific factor 1 (emotional response to COVID-19): A general factor underlying all items, plus a specific factor also underlying items 1, 2, 4, and 5. The two factors are uncorrelated.

- Model 5. Bifactor model with only specific factor 2 (physiological responses to COVID19): A general factor underlying all items, plus a specific factor also underlying items 3,6 , and 7. The two factors are uncorrelated.

Models 4 and 5 allow to discern if some of the specific factor is not needed in order to achieve a good model fit. Therefore, models 4 and 5 are alternative models to compare with model 3.

All these models can be seen graphically in Fig. 1. These models are estimated and tested, and their goodness-of-fit indices are presented in Table 1. In this table, it can be seen that model fit of all models is good according to the CFI and SRMR, with values well above .95 and SRMR well below .08. RMSEA values are not so good, but this is usual when models with not many degrees of freedom are considered (Breivik and Olsson 2001; Kenny et al. 


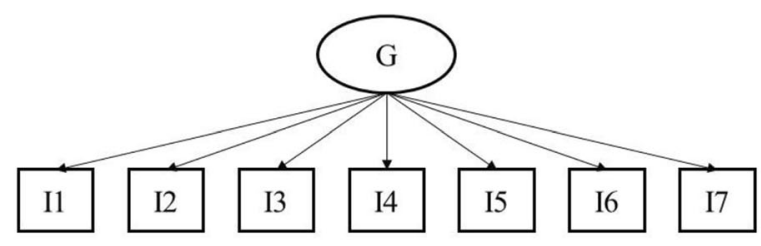

Model 1

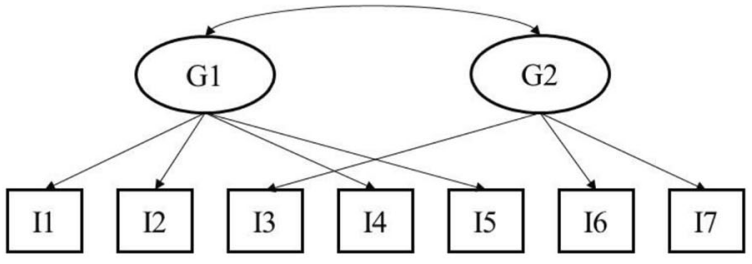

Model 2

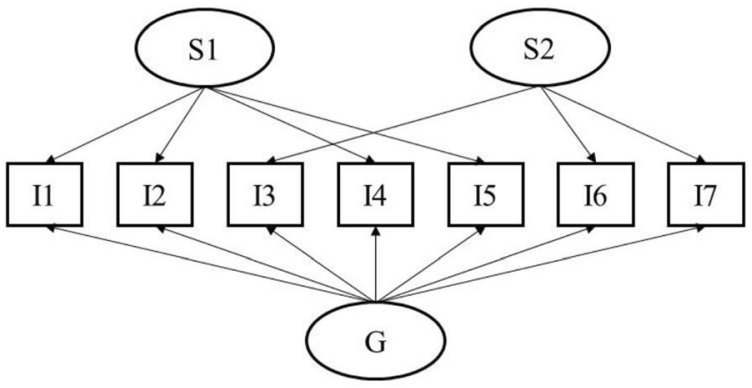

Model 3

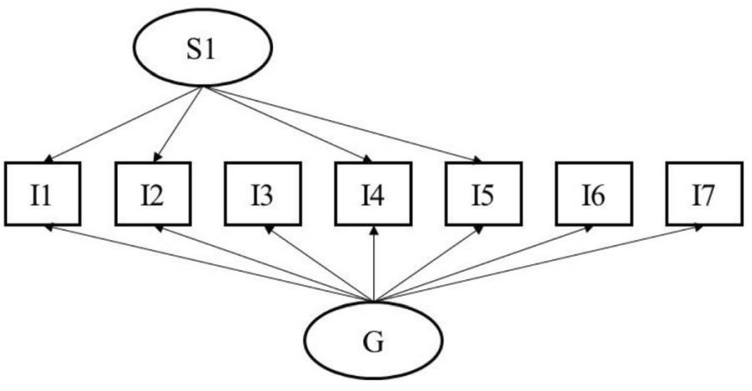

Model 4

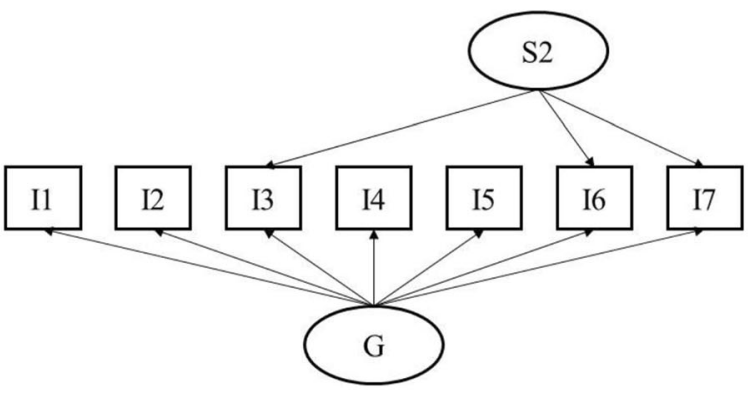

Model 5

Notes: $G=$ General factors, $S=$ Specific factors

Fig. 1 Tested models. G general factors and S specific factors 
2014). When models are compared, the best fitting model in absolute terms is the bifactor model (model 3).

However, these models are very different in terms of parsimony, and additionally, some are nested. Therefore, statistical tests between nested models may be applied to test if the difference in model fit can still be considered random, and therefore, the more parsimonious model is preferred over the more complex one. In this vein also, Table 1 shows the chi-square differences between models 2 and 3 against model 1 (one single factor) and also between models 4 and 5 against model 3 (bifactor). The chi-square comparisons of model 2 and model 3 against model 1 (one factor) made clear that only one factor is not the best solution for the factor structure of the scale. Then, the two bifactor models with only one specific factor (models 4 and 5) were statistically compared to model 3, in order to understand if the two specific factors are needed for a best fit to the data. Whenever model 5 was clearly worse than model 3, this was not the case with model 4 when compared to model 3: the difference was statistically significant in favor of model 3 but only at the $p<.05$ level and not at the more astringent $p<.01$. Fit indices of model 4 also pointed out that model fit of this (more parsimonious model) was excellent. All in all, and regarding the overall fit, the model that could be retained is model 4 .

A careful look at the standardized loadings in all models may be necessary in order to make a better decision about the model to retain. These loadings are presented in Table 2. In general, it can be seen across models that all items load quite high in the general factor. When specific factors are introduced (models 3 to 5), the loadings for these specific factors are, in general, relatively low, with the exception of model 4 , in which the loadings of three items (1, 2, and 4) are of a considerable amount. In sum, the standardized loadings also point out at model 4 as the best representation of the observed data (bifactor model with only specific factor 1 that expresses the emotional response to COVID-19).

\section{Reliability Estimates}

Composite reliability indexes, as measures of internal consistency, were calculated for all factors in all models. CRI for model 1 was .899 . CRIs for model 2 were .838 for the first factor and .837 for the second one. Regarding the bifactor with one general factor and two specific factors (model 3), the CRIs were, respectively, .882, .300, and .292. When only the specific factor 1 was estimated (model 4), the CRI for the general factor was .878, whereas the CRI for the specific factor was .411 . Finally, CRIs for the general and specific factor (two) in model 5 were .889 and .346 , respectively.

Table 1 Model fit indexes

\begin{tabular}{lrlllllllll}
\hline Models & $\chi^{2}$ & df & $p$ & $\Delta \chi 2$ & $\Delta$ df & $p$ & RMSEA 90\%CI & SRMR & CFI \\
\hline 1. One-factor & 88.51 & 14 & $<.001$ & - & - & - & $.115[.093-.139]$ & .034 & .976 \\
2. Two correlated factors & 53.63 & 13 & $<.001$ & 27.94 & 1 & $<.001$ & $.088[.065-.114]$ & .025 & .987 \\
3. Bifactor 1 general 2 specific & 6.35 & 7 & .498 & 70.27 & 7 & $<.001$ & $.000[.000-.058]$ & .009 & 1 \\
$\begin{array}{l}\text { 4. Bifactor 1 general only 1st } \\
\quad\end{array}$ & 18.82 & 10 & .042 & 10.60 & 3 & .015 & $.047[.008-.079]$ & .014 & .997 \\
$\quad \begin{array}{l}\text { specific } \\
\text { 5. Bifactor 1 general only 2nd } \\
\quad \text { specific }\end{array}$ & 48.16 & 11 & $<.001$ & 33.71 & 4 & $<.001$ & $.092[.066-.119]$ & .023 & .988 \\
\hline
\end{tabular}

The chi-square difference tests are comparing with one factor, except models 4 and 5 that compare to model 3 
Table 2 Standardized factor loadings for all the models

\begin{tabular}{|c|c|c|c|c|c|c|c|c|c|c|}
\hline \multirow[b]{2}{*}{ Item } & \multirow{2}{*}{$\begin{array}{l}\text { Model } 1 \\
\text { G }\end{array}$} & \multicolumn{2}{|c|}{ Model 2} & \multicolumn{3}{|c|}{ Model 3} & \multicolumn{2}{|c|}{ Model 4} & \multicolumn{2}{|c|}{ Model 5} \\
\hline & & G1 & G2 & G & $\mathrm{S} 1$ & $\mathrm{~S} 2$ & G & $\mathrm{S} 1$ & G & $\mathrm{S} 2$ \\
\hline 1 & .723 & .739 & & .665 & .784 & & .599 & .628 & .739 & \\
\hline 2 & .576 & .588 & & .545 & .205 & & .501 & .330 & .588 & \\
\hline 3 & .648 & & .668 & .606 & & .268 & .669 & & .584 & .321 \\
\hline 4 & .758 & .772 & & .732 & .194 & & .678 & .371 & .773 & \\
\hline 5 & .852 & .889 & & .900 & .001 & & .830 & .194 & .888 & \\
\hline 6 & .798 & & .821 & .739 & & .574 & .822 & & .716 & .572 \\
\hline 7 & .849 & & .884 & .817 & & .203 & .878 & & .796 & .264 \\
\hline
\end{tabular}

In addition, relative omegas were calculated for the best fitting model (model 4) in order to know the amount of reliable variance attributable to the general and specific factors in this model. The relative omega for the general factor was .913, while for the specific factor was .261 .

\section{Relationships with External Variables}

A structural equation model has been estimated, in which several antecedents or background variables, as well as consequents of fear of COVID-19 are considered. The final outcome of this model is mental health at the latent level (see Fig. 2). This outcome was measured with three indicators, a measure of mental health, and indicators of anxiety and depression. Previous to include the three indicators of mental health (scales of mental health, anxiety, and depression), a CFA at the item level was estimated in order to be sure that the items belong to the proposed factors and also in order to estimate reliabilities of the three scales. The CFA model adequately fitted the data: $\chi^{2}(24)=275.69, p<.001$, RMSEA $=.162$ CI90\%[.145-.179], $\mathrm{CFI}=.940, \mathrm{SRMR}=.050$. Moreover, the CRIs calculated for the three dimensions of mental health were adequate, being .801 for mental health, .876 for anxiety, and .895 for depression.

The model and its standardized estimates are presented in Fig. 2. The antecedent variables were age, gender, having or not a relative diagnosed with COVID, having or not a close friend diagnosed with COVID, and the amount of information received on COVID. This model had a

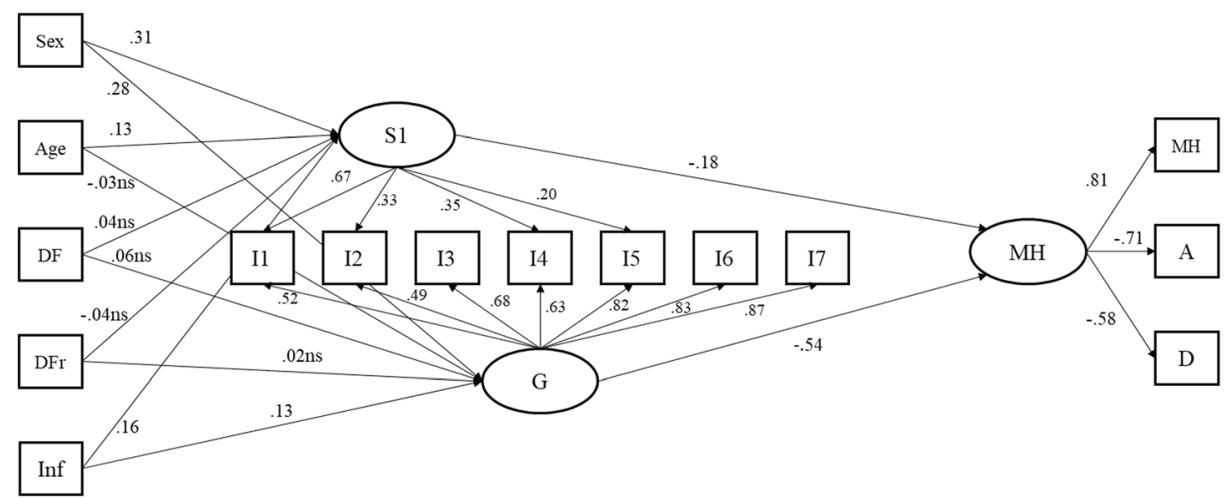

Fig. 2 Structural model to test for he relationships among variables 
very good fit: $\chi^{2}(69)=158.5, p<.001, \mathrm{RMSEA}=.057$ CI90\%[.045-.069], CFI $=.973$, $\mathrm{SRMR}=.048$.

Standardized results (see Fig. 2) pointed out the large effect fear of COVID had on mental health $\left(R^{2}=.346\right)$. Regarding the background variables, women had more fear of COVID than men; age was only positively related with the specific factor 1 ; neither having a diagnose of COVID in a relative nor a friend had effects on fear of COVID; and the amount of information on the virus positively affected the fear of COVID. Overall, the background variables explained $11.1 \%$ of the variance in the general factor and $14.6 \%$ of the specific factor.

\section{Discussion}

The aim of this study was to evaluate the psychometric properties of the FCV-19S for use in older adults in Peru. In general, the findings provide further support to the evidence of validity and reliability of the FCV-19S, demonstrating that the Spanish version has robust psychometric properties for its use in older adults. Several studies on the factor structure of the FCV-19S have supported a one-dimensional model (for example, Ahorsu et al. 2020; Alyami et al. 2020; Haktanir et al. 2020; Sakib et al. 2020; Satici et al. 2020; Soraci et al. 2020; Tsipropoulou et al. 2020; Winter et al. 2020). However, the confirmatory analyses of the scale in Perú (HuarcayaVictoria et al. 2020) gave support to the presence of a bifactor model, made up of one general factor and two specific ones, emotional and physiological response. That is, the previous validation in the general population of the scale in Peru supports that each item of the scale has two sources of variation, a general factor of fear of the virus plus a specific fear response that it is either emotional or physiological. Current results are somewhere in between. We found that a single dimension was not the best representation of the data, and indeed a bifactor structure was needed to get a better fit. However, the bifactorial structure that, in our opinion, best represents the responses of older adults only included the emotional response as a specific factor, while the other factor, which included the physiological response, was mainly due to the specific variance made by a single indicator (item 6). In any case, the reliability estimates clearly indicated that most of the explained variance was due to the single dimension of fear of COVID-19, and therefore, the scale can be used as unidimensional. This result may well explain the somehow non-coincident structures found in the literature. On the other hand, the study supports the idea of considering fear of COVID-19 as a multidimensional construct, which allows researchers and mental health professionals to differentiate between fear of COVID-19 and its associated symptoms (Bitan et al. 2020). Therefore, it allows obtaining a total scale score as well as an independent score for the emotional symptoms.

Likewise, the results indicated that the Spanish version of the FCV-19S had adequate reliability in terms of internal consistency, which is a finding consistent with previous studies carried out with samples of different characteristics (Ahorsu et al. 2020; Alyami et al. 2020; Bitan et al. 2020; Haktanir et al. 2020; Reznik et al. 2020; Sakib et al. 2020; Satici et al. 2020; Soraci et al. 2020; Tsipropoulou et al. 2020; Winter et al. 2020), including the Peruvian (Huarcaya-Victoria et al. 2020). This would indicate that, despite the different versions, the measurements obtained with the FCV-19S are consistent and very stable.

Regarding the structural equation model estimated, we think it gives relevant information on concurrent validity of the scale. The relationships between different antecedent variables and the consequences of fear of COVID-19 suggest that the Spanish version of the FCV-19S has adequate evidence of validity in relation to other variables. Fear generates psychological 
reactions that allow the individual to face threatening situations (Sakib et al. 2020). In this sense, fear of COVID-19 has a great effect on the indicators of mental health considered. The findings suggest that higher levels of fear of COVID-19 generate higher levels of anxiety and depression and, in general, poor mental health. These results are similar to those reported in other studies carried out on different samples (Ahorsu et al. 2020; Alyami et al. 2020; Huarcaya-Victoria et al. 2020; Shigemura et al., 2020).

Results on antecedent variables also offer interesting information. Being a woman significantly predicts higher levels of fear of COVID-19. This difference is in line with previous research that indicated that the COVID-19 pandemic generates a greater negative psychological impact on women compared to men (Broche-Pérez et al. 2020; Wang et al. 2020). This could be related to the fact that women tend to show more reactivity in fear-related neural networks (Liu et al. 2020). On the other hand, having a family member or friend diagnosed with COVID-19 had no effect on fear of COVID-19. This is not in agreement with other studies, where it is suggested that people experienced greater fear when contacting people infected with COVID-19 (Lin 2020; Thombs et al. 2020). Finally, the greater the amount of information received about COVID-19, the greater the fear of the disease. This suggests that a longer time of exposure to news about the increase in diagnosed cases and deaths during the pandemic leads older adults to increment their fear as well as other symptoms such as anxiety and depression (Lin 2020).

This study has limitations. First, it is based on self-report measures which can generate the presence of biases for social convenience and/or memory effects. In this sense, it is recommended that future studies use other methodologies, such as in-depth qualitative interviews or case studies. Second, we used snowball sampling which makes very unlikely the sample being representative of the Peruvian older adult population. This sampling procedure has overrepresented older women compared to older men, and therefore, potential bias due to gender may be present. Nevertheless, alpha for men and women were calculated and statistically compared for potential differences. Alpha for men was .826 and for women .848 , and the difference was not statistically significant: $\chi^{2}(1)=0.598, p=.439$ (Diedenhofen and Musch 2016). Therefore, future studies should use nationally representative samples. Likewise, since the older adults were not institutionalized, it would also be useful to replicate the study in this population. Third, the study used a cross-sectional design, so the reported relationships between the variables do not provide causal information. Because the development of the pandemic generates changes in social rules and behavior, future research should use longitudinal designs to assess causal relationships between antecedents, outcomes, and fear of COVID-19. A better understanding on the relationships over time between fear of COVID, changing rates of infection and death, and the social responses to the pandemic would give rise to an important line of research (Perz et al. 2020). Fourth, the fact that most of the participants were women could affect the generalizability of the findings. Finally, the stability of the FCV-19S over time was not examined. Therefore, future studies should incorporate test-retest reliability measures.

Despite the limitations, the study has various strengths. First, having an instrument to assess fear related to COVID-19 could be important as an outcome measure or a possible explanatory factor in investigations conducted with older adults during the COVID-19 pandemic. Second, to have a measure to identify the levels of this fear among different groups of older adults (institutionalized or non-institutionalized, from different regions of the country, etc.) and their relationships with various sociodemographic variables (such as gender, time exposed to information on the COVID-19, diagnosis of COVID-19 in family and friends, etc.) would allow decision makers and various mental health professionals to locate risk groups during the 
Covid-19 pandemic. Not having an adequate understanding of the fear generated by COVID19 in vulnerable groups, such as older adults, makes difficult to identify the most useful prevention and intervention programs (Pakpour and Griffiths 2020).

In conclusion, the results showed that the Spanish version of the FCV-19S has adequate psychometric properties and can be used to assess fear of COVID-19 during the pandemic in Peruvian older adults. Nevertheless, it is necessary to carry out more research, in different regions of Peru and Latin American countries, to better understand the usefulness of the FCV19S in the implementation of interventions and policies aimed at improving the mental health of older adults.

\section{Compliance with Ethical Standards}

Competing Interest The authors declare that they have no competing interest.

\section{References}

Ahorsu, D. K., Lin, C. Y., Imani, V., Saffari, M., Griffiths, M. D., \& Pakpour, A. H. (2020). The fear of COVID19 scale: Development and initial validation. International Journal of Mental Health and Addiction. https:// doi.org/10.1007/s11469-020-00270-8.

Alyami, M., Henning, M., Krägeloh, C. U., \& Alyami, H. (2020). Psychometric evaluation of the Arabic version of the fear of COVID-19 scale. International Journal of Mental Health and Addiction, 1-14. https://doi.org/ 10.1007/s11469-020-00316-X.

Asmundson, G. J., \& Taylor, S. (2020). Coronaphobia: Fear and the 2019-nCoV outbreak. Journal of Anxiety Disorders, 70, 102196. https://doi.org/10.1016/j.janxdis.2020.102196.

Atkinson, R., \& Flint, J. (2004). Snowball sampling. In M. S. Lewis-Beck, A. Bryman, \& T. F. Liao (Eds.), The SAGE encyclopedia of social science research methods (pp. 1044-1045). Thousand Oaks: Sage. https://doi. org/10.4135/9781412950589.

Ato, M., López-García, J. J., \& Benavente, A. (2013). Un sistema de clasificación de los diseños de investigación en psicología. Anales de Psicología, 29(3), 1038-1059. https://doi.org/10.6018/analesps.29.3.178511.

Baltar, F., \& Brunet, I. (2012). Social research 2.0: Virtual snowball sampling method using Facebook. Internet Research, 22(1), 57-74. https://doi.org/10.1108/10662241211199960.

Baud, D., Qi, X., Nielsen-Saines, K., Musso, D., Pomar, L., \& Favre, G. (2020). Real estimates of mortality following COVID-19 infection. The Lancet Infectious Diseases, 20(7), P773. https://doi.org/10.1016/S14733099(20)30195-X.

Berwick, D. M., Murphy, J. M., Goldman, P. A., Ware Jr., J. E., Barsky, A. J., \& Weinstein, M. C. (1991). Performance of a five-item mental health screening test. Medical Care, 29(2), 169-176 https://www.jstor. org/stable/3766262.

Bitan, D. T., Grossman-Giron, A., Bloch, Y., Mayer, Y., Shiffman, N., \& Mendlovic, S. (2020). Fear of COVID19 scale: Psychometric characteristics, reliability and validity in the Israeli population. Psychiatry Research, 289, 113100. https://doi.org/10.1016/j.psychres.2020.113100.

Breivik, E., \& Olsson, U. H. (2001). Adding variables to improve fit: The effect of model size on fit assessment in LISREL. In R. Cudeck, S. Du Toit, \& D. Sörbom (Eds.), Structural equation modeling: Present and future. A Festschrift in honor of Karl Jöreskog (pp. 169-194). Lincolnwood: Scientific Software International.

Broche-Pérez, Y., Fernández-Fleites, Z., Jiménez-Puig, E., Fernández-Castillo, E., \& Rodríguez-Martin, B. C. (2020). Gender and fear of COVID-19 in a Cuban population sample. International Journal of Mental Health and Addiction, 1-9. https://doi.org/10.1007/s11469-020-00343-8.

Carriedo, A., Cecchini, J. A., Fernandez-Rio, J., \& Méndez-Giménez, A. (2020). COVID-19, psychological wellbeing and physical activity levels in older adults during the nationwide lockdown in Spain. The American Journal of Geriatric Psychiatry, 28(11), 1146-1155. https://doi.org/10.1016/j.jagp.2020.08.007.

Caycho-Rodríguez, T., Barboza-Palomino, M., \& Carranza, R. F. (2019a). Prevalencia de depresión en una muestra de adultos mayores peruanos no institucionalizados. Enfermería Clínica, 29(1), 58-59. https://doi. org/10.1016/j.enfcli.2018.09.006. 
Caycho-Rodríguez, T., Barboza-Palomino, M., \& Domínguez-Vergara, J. (2019b). Funcionamiento cognitivo y comportamental, y calidad de vida en adultos mayores. Enfermería Clínica, 29(1), 57-58. https://doi.org/10. 1016/j.enfcli.2018.04.001.

Caycho-Rodríguez, T., Cabrera-Orosco, I., Noé-Grijalva, M., \& Carranza Esteban, R. F. (2020a). Nuevos aportes para la comprensión de la ideación y el intento suicida en adultos mayores peruanos. Revista Española de Geriatría y Gerontología, 55(3), 180-181. https://doi.org/10.1016/j.regg.2019.10.010.

Caycho-Rodríguez, T., Carbajal-León, C., \& Noé-Grijalva, M. (2020b). Loneliness, sex and general health perception in Peruvian older adults. Revista Española de Geriatría y Gerontología, 55(3), 187-188. https:// doi.org/10.1016/j.regg.2020.02.005.

Caycho-Rodríguez, T., Tomás, J. M., Ventura-León, J., Carranza Esteban, R. F., Oblitas Guadalupe, L. A., Reyes-Bossio, M., ... \& Cabrera-Orosco, I. (2020c). Factorial validity and invariance analysis of the five items version of mindful awareness attention scale in older adults. Aging \& Mental Health, 1-10. https://doi. org/10.1080/13607863.2020.1716685.

Caycho-Rodríguez, T., Tomás, J. M., Ventura-León, J., Sancho, P., Cabrera-Orosco, I., \& BarbozaPalomino, M. (2020d). Medición de la voluntad de vivir en adultos mayores: adaptación transcultural, validez y confiabilidad de la Will-to-Live Scale. Enfermería Clínica. https://doi.org/10. 1016/j.enfcli.2020.06.078.

Caycho-Rodríguez, T., Vilca, L. W., Plante, T. G., Carbajal-León, C., Cabrera-Orosco, I., Cadena, C. H. G., \& Reyes-Bossio, M. (2020e). Spanish version of the Santa Clara brief compassion scale: Evidence of validity and factorial invariance in Peru. Current Psychology, 1-16. https://doi.org/10.1007/s12144-020-00949-0.

Diedenhofen, B., \& Musch, J. (2016). Cocron: A web interface and R package for the statistical comparison of Cronbach's alpha coefficients. International Journal of Internet Science, 11, 51-60.

Dominguez-Lara, S. A., \& Centeno-Leyva, S. B. (2017). Prevalencia de depresión en adultos mayores institucionalizados en Lima Metropolitana. Enfermería Clínica, 27(1), 59-60. https://doi.org/10.1016/j. enfcli.2016.07.009.

Dueber, D. M. (2017). Bifactor indices calculator: A Microsoft Excelbased tool to calculate various indices relevant to bifactor CFA models. https://doi.org/10.13023/edp.tool.01 [Available at http://sites.education. uky.edu/apslab/resources/]

Gozzer, E., Canchihuamán, F., \& Espinoza, R. (2020). COVID-19 y la necesidad de actuar para mejorar las capacidades del Perú frente a las pandemias. Revista Peruana de Medicina Experimental y Salud Pública, 37(2), 371-373. https://doi.org/10.17843/rpmesp.2020.372.5410.

Haktanir, A., Seki, T., \& Dilmaç, B. (2020). Adaptation and evaluation of Turkish version of the fear of COVID19 scale. Death Studies, 1-9. https://doi.org/10.1080/07481187.2020.1773026.

Hancock, G. R., \& An, J. (2018). Digital items module 2: Scale reliability in structural equation modeling. Educational Measurement: Issues and Practice, 37, 73-74. https://doi.org/10.1111/emip.12210.

Hancock, G. R., \& Mueller, R. O. (2013). Structural equation modeling: A second course (2nd ed.) information age publishing. www.infoagepuv.com

Huang, Y., \& Zhao, N. (2020). Generalized anxiety disorder, depressive symptoms and sleep quality during COVID-19 outbreak in China: A web-based cross-sectional survey. Psychiatry Research, 288, 112954. https://doi.org/10.1016/j.psychres.2020.112954.

Huarcaya-Victoria, J. (2020). Consideraciones sobre la salud mental en la pandemia de COVID-19. Revista Peruana de Medicina Experimental y Salud Pública, 37(2), 327-334.

Huarcaya-Victoria, J., Villarreal-Zegarra, D., Podestà, A., \& Luna-Cuadros, M. A. (2020). Psychometric properties of a Spanish version of the fear of COVID-19 scale in general population of Lima, Peru. International Journal of Mental Health and Addiction, 1-14. https://doi.org/10.1007/ s11469-020-00354-5.

Kenny, D. A., Kaniskan, B., \& McCoach, B. (2014). The performance of RMSEA in models with small degrees of freedom. Sociological Research Methods, 44, 486-507. https://doi.org/10.1177/0049124114543236.

Kroenke, K., Spitzer, R. L., \& Williams, J. B. (2003). The patient health questionnaire-2: Validity of a two-item depression screener. Medical Care, 41(11), 1284-1292.

Kroenke, K., Spitzer, R. L., Williams, J. B., Monahan, P. O., \& Löwe, B. (2007). Anxiety disorders in primary care: Prevalence, impairment, comorbidity, and detection. Annals of Internal Medicine, 146(5), 317-325.

Lin, C. Y. (2020). Social reaction toward the 2019 novel coronavirus (COVID-19). Social Health and Behavior, 3(1), 1-2. https://doi.org/10.4103/SHB.SHB 1120.

Liu, N., Zhang, F., Wei, C., Jia, Y., Shang, Z., Sun, L., Wu, L., Sun, Z., Zhou, Y., Wang, Y., \& Liu, W. (2020). Prevalence and predictors of PTSS during COVID-19 outbreak in China hardest-hit areas: Gender differences matter. Psychiatry Research, 287, 112921. https://doi.org/10.1016/j.psychres.2020.112921.

Marsh, H. W., Hau, K. T., \& Wen, Z. (2004). In search of golden rules: Comment on hypothesis-testing approaches to setting cutoff values for fit indexes and dangers in overgeneralizing Hu and Bentler's (1999) findings. Structural Equation Modeling, 11(3), 320-341. https://doi.org/10.1207/s15328007sem1103_2. 
Masuyama, A., Shinkawa, H., \& Kubo, T. (2020). Validation and psychometric properties of the Japanese version of the fear of COVID-19 scale among adolescents. International Journal of Mental Health and Addiction, 1-11. https://doi.org/10.1007/s11469-020-00368-z.

Mertens, G., Gerritsen, L., Duijndam, S., Salemink, E., \& Engelhard, I. M. (2020). Fear of the coronavirus (COVID-19): Predictors in an online study conducted in march 2020. Journal of Anxiety Disorders, 74, 102258. https://doi.org/10.1016/j.janxdis.2020.102258.

Morley, J. E., \& Vellas, B. (2020). COVID-19 and older adult. The Journal of Nutrition, Health \& Aging, 24(4), 364-365. https://doi.org/10.1007/s12603-020-1349-9.

Muthén, L. K., \& Muthén, B. O. (1998-2017). Mplus User's Guide (Eighth ed.). Los Angeles: Muthén \& Muthén.

O’Brien, N., Barboza-Palomino, M. M., Ventura-León, J., Caycho-Rodríguez, M. T., Sandoval-Díaz, J. S., López-López, W., \& Salas, G. (2020). Nuevo coronavirus (COVID-19). Un análisis bibliométrico. Revista Chilena de Anestesia, 49, 408-415. https://doi.org/10.25237/revchilanestv49n03.020.

Pakpour, A. H., \& Griffiths, M. D. (2020). The fear of COVID-19 and its role in preventive behaviors. Journal of Concurrent Disorders. http://irep.ntu.ac.uk/id/eprint/39561/1/1313636 Griffiths.pdf

Perz, C. A., Lang, B. A., \& Harrington, R. (2020). Validation of the fear of COVID-19 scale in a US college sample. International journal of mental health and addiction, 1-11. https://doi.org/10.1007/s11469-02000356-3.

Rajkumar, R. P. (2020). COVID-19 and mental health: A review of the existing literature. Asian Journal of Psychiatry, 52, 102066. https://doi.org/10.1016/j.ajp.2020.102066.

Raykov, T., \& Pohl, S. (2013). Essential unidimensionality examination for multicomponent scales: An interrelationship decomposition approach. Educational and Psychological Measurement, 73(4), 581-600. https://doi.org/10.1177/0013164412470451.

Reise, S. P. (2012). The rediscovery of bifactor measurement models. Multivariate Behavioral Research, 47(5), 667-696. https://doi.org/10.1080/00273171.2012.715555.

Reise, S. P., Moore, T. M., \& Haviland, M. G. (2010). Bifactor models and rotations: Exploring the extent to which multidimensional data yield univocal scale scores. Journal of Personality Assessment, $92(6), 544$ 559. https://doi.org/10.1080/00223891.2010.496477.

Reznik, A., Gritsenko, V., Konstantinov, V., Khamenka, N., \& Isralowitz, R. (2020). COVID-19 fear in Eastern Europe: Validation of the fear of COVID-19 scale. International journal of mental health and addiction, 1-6. https://doi.org/10.1007/s11469-020-00283-3.

Rivera-Riquelme, M., Piqueras, J. A., \& Cuijpers, P. (2019). The revised mental health inventory-5 (MHI-5) as an ultra-brief screening measure of bidimensional mental health in children and adolescents. Psychiatry Research, 274, 247-253. https://doi.org/10.1016/j.psychres.2019.02.045.

Rodriguez, A., Reise, S. P., \& Haviland, M. G. (2016a). Applying bifactor statistical indices in the evaluation of psychological measures. Journal of Personality Assessment, 98(3), 223-237. https://doi.org/10.1080/ 00223891.2015 .1089249 .

Rodriguez, A., Reise, S. P., \& Haviland, M. G. (2016b). Evaluating bifactor models: Calculating and interpreting statistical indices. Psychological Methods, 21(2), 137-150. https://doi.org/10.1037/met0000045.

Rodriguez-Morales, A. J., Gallego, V., Escalera-Antezana, J. P., Méndez, C. A., Zambrano, L. I., FrancoParedes, C., et al. (2020a). COVID-19 in Latin America: The implications of the first confirmed case in Brazil. Travel Medicine and Infectious Disease, 35, 101613. https://doi.org/10.1016/j.tmaid.2020.101613.

Rodriguez-Morales, A. J., Sánchez-Duque, J. A., Hernández Botero, S., Pérez-Díaz, C. E., Villamil-Gómez, W. E., Méndez, C. A., et al. (2020b). Preparación y control de la enfermedad por coronavirus 2019 (COVID-19) en América Latina. Acta Medica Peruana, 37(1), 3-7. https://doi.org/10.35663/amp.2020.371.909.

Sakib, N., Bhuiyan, A. I., Hossain, S., Al Mamun, F., Hosen, I., Abdullah, A. H., .. \& Sikder, M. T. (2020). Psychometric validation of the Bangla Fear of COVID-19 Scale: Confirmatory factor analysis and Rasch analysis. International Journal of Mental Health and Addiction, 1-12. https://doi.org/10.1007/s11469-02000289-x

Sánchez-Duque, J. A., Arce-Villalobos, L. R., \& Rodríguez-Morales, A. J. (2020). Enfermedad por coronavirus 2019 (COVID-19) en América Latina: papel de la atención primaria en la preparación y respuesta. Atencion Primaria, 52(6), 369-372. https://doi.org/10.1016/j.aprim.2020.04.001.

Satici, B., Gocet-Tekin, E., Deniz, M. E., \& Satici, S. A. (2020). Adaptation of the fear of COVID-19 scale: Its association with psychological distress and life satisfaction in Turkey. International Journal of Mental Health and Addiction, 1-9. https://doi.org/10.1007/s11469-020-00294-0.

Shigemura, J., Ursano, R. J., Morganstein, J. C., Kurosawa, M., \& Benedek, D. M. (2020). Public responses to the novel 2019 coronavirus (2019-nCoV) in Japan: Mental health consequences and target populations. Psychiatry and Clinical Neurosciences, 74(4), 281-282. https://doi.org/10.1111/pcn.12988.

Soper, D.S. (2020). A-priori sample size calculator for structural equation models [Software]. Retrieved from http://www.danielsoper.com/statcalc. 
Soraci, P., Ferrari, A., Abbiati, F. A., Del Fante, E., De Pace, R., Urso, A., \& Griffiths, M. D. (2020). Validation and psychometric evaluation of the Italian version of the fear of COVID-19 scale. International Journal of Mental Health and Addiction, 1-10. https://doi.org/10.1007/s11469-020-00277-1.

Steinman, M. A., Perry, L., \& Perissinotto, C. M. (2020). Meeting the care needs of older adults isolated at home during the COVID-19 pandemic. JAMA Internal Medicine, 180(6), 819-820. https://doi.org/10.1001/ jamainternmed.2020.1661.

Tanaka, J. S. (1993). Multifaceted conceptions of fit in structural equation models. In K. A. Bollen \& J. S. Long (Eds.), Testing structural equation models. Newbury (pp. 10-39). Park: Sage.

Taylor, S. (2019). The psychology of pandemics: Preparing for the next global outbreak of infectious disease. In Newcastle upon Tyne. Cambridge: Cambridge Scholars Publishing.

Taylor, S., Landry, C., Paluszek, M., Fergus, T. A., McKay, D., \& Asmundson, G. J. (2020). Development and initial validation of the COVID stress scales. Journal of Anxiety Disorders, 72, 102232. https://doi.org/10. 1016/j.janxdis.2020.102232.

Thombs, B. D., Bonardi, O., Rice, D. B., Boruff, J. T., Azar, M., He, C., et al. (2020). Curating evidence on mental health during COVID-19: A living systematic review. Journal of Psychosomatic Research, 133, 110113. https://doi.org/10.1016/j.jpsychores.2020.110113.

Tsipropoulou, V., Nikopoulou, V. A., Holeva, V., Nasika, Z., Diakogiannis, I., Sakka, S., ... \& Parlapani, E. (2020). Psychometric properties of the Greek version of FCV-19S. International Journal of Mental Health and Addiction, 1-10. https://doi.org/10.1007/s11469-020-00319-8

Veit, C. T., \& Ware, J. E. (1983). The structure of psychological distress and well-being in general populations. Journal of Consulting and Clinical Psychology, 51(5), 730-742. https://doi.org/10.1037/0022-006X.51.5. 730.

Wang, C., Pan, R., Wan, X., Tan, Y., Xu, L., Ho, C. S., \& Ho, R. C. (2020). Immediate psychological responses and associated factors during the initial stage of the 2019 coronavirus disease (COVID-19) epidemic among the general population in China. International Journal of Environmental Research and Public Health, 17(5), 1729. https://doi.org/10.3390/ijerph17051729.

Winter, T., Riordan, B. C., Pakpour, A. H., Griffiths, M. D., Mason, A., Poulgrain, J. W., \& Scarf, D. (2020). Evaluation of the English version of the fear of COVID-19 scale and its relationship with behavior change and political beliefs. International Journal of Mental Health and Addiction, 1-11. https://doi.org/10.1007/ s11469-020-00342-9.

Yang, Y., Li, W., Zhang, Q., Zhang, L., Cheung, T., \& Xiang, Y. T. (2020). Mental health services for older adults in China during the COVID-19 outbreak. The Lancet Psychiatry, 7(4), e19.I. https://doi.org/10.1016/ S2215-0366(20)30079-1.

Publisher's Note Springer Nature remains neutral with regard to jurisdictional claims in published maps and institutional affiliations.

\section{Affiliations}

\section{Tomás Caycho-Rodríguez ${ }^{1,2} \cdot$ José M. Tomás ${ }^{3} \cdot$ Miguel Barboza-Palomino ${ }^{1} \cdot$ José Ventura-León ${ }^{1} \cdot$ Miguel Gallegos ${ }^{4,5} \cdot$ Mario Reyes-Bossio $^{6} \cdot$ Lindsey W. Vilca $^{7}$}

1 Facultad de Ciencias de la Salud, Universidad Privada del Norte, Lima, Peru

2 Facultad de Ciencias de la Salud, Universidad Privada del Norte, Av. Alfredo Mendiola 6062, Los Olivos, Lima, Peru

3 Department of Methodology of the Behavioural Sciences, University of Valencia, Valencia, Spain

4 Facultad de Ciencias de la Salud, Universidad Católica del Maule, Talca, Chile

5 Consejo Nacional de Investigaciones Científicas y Técnicas, CONICET, Buenos Aires, Argentina

6 Facultad de Psicología, Universidad Peruana de Ciencias Aplicadas, Lima, Peru

7 Departamento de Psicología, Universidad Peruana Unión, Lima, Peru 